\title{
Intravenous infusions of heparin and penicillins
}

\author{
J. JACOBS, DINA KLETTER ${ }^{1}$, E. SUPERSTINE, K. R. HILL, B. LYNN, AND \\ R. A. WEBB
}

From the Department of Pharmacy Services, Rothschild Hadassah University Hospital, Jerusalem, Israel, and Beccham Research Laboratories, Worthing, Sussex

SYNOPSIS The chemical stability and anticoagulant activity of heparin $(20 \mathrm{U} / \mathrm{ml})$ were studied in five intravenous fluids at room temperature. Heparin remained stable and active for 24 hours in normal saline, but there was a rapid inactivation of 40 to $55 \%$ in solutions containing dextrose or lactate, as measured by chemical and biological methods.

High concentrations of benzylpenicillin, ampicillin, or methicillin had no effect on heparin activity in normal saline or dextrose $5 \%$ : nor was the stability of the penicillins in these fluids affected to any marked extent by the presence of heparin. Ampicillin was, however, found to be unstable in dextrose $5 \%$, and it would be preferable for it not to be added to dextrose infusions. It is concluded that heparin may be given intravenously in normal saline with benzylpenicillin, ampicillin, or methicillin but several other antibiotics were found to be unsuitable for concurrent infusion with heparin.

Heparin is frequently given by intravenous infusion, either alone or in conjunction with other agents. A survey of drugs administered by this route in the Hadassah University Hospital showed that heparin sodium was involved in $11 \%$ of all instances where one or more drugs were added to intravenous bottles (Jacobs, 1972). It may be used either as a primary therapeutic agent in the prophylaxis and treatment of thromboembolic disorders, or incorporated as a secondary agent to prevent blockage of the intravenous needle due to local clotting. As such infusions may be administered over periods as long as 24 hours, it is essential that the vehicle chosen and any drug added should not significantly reduce the anticoagulant activity of the heparin. It is also important that the heparin should not adversely affect the activity of the other drug.

Despite many years of clinical usage, data concerning the stability of heparin in intravenous fluids are both scarce and conflicting, and there is little information about its physicochemical interaction with other agents. Antibiotics, particularly benzylpenicillin and the semi-synthetic penicillins, are among the agents most often mixed with heparin in intravenous infusions. Indeed, intravascular

\footnotetext{
2Part of the work is incorporated in the thesis submitted to the Hebrew University by Dina Kletter for the requirements of the M Pharm degree.

Received for publication 16 July 1973.
}

coagulation has been reported as a complication of Gram-negative septicaemia (Preston, Malia, Sworn, and Blackburn, 1973). Joint research was therefore undertaken by Beecham Research Laboratories and the Department of Pharmacy Services of the Hadassah University Hospital to determine the stability profile of heparin in a range of common intravenous fluids, and to assess the compatibility and stability of mixtures of heparin with benzylpenicillin, ampicillin, or methicillin in normal saline and $5 \%$ dextrose solution. The suitability of several other antibiotics for infusion with heparin was also investigated.

\section{Materials and Methods}

\section{HEPARIN ASSAYS}

Heparin sodium $147 \mathrm{U} / \mathrm{mg}$ (Organon), derived from mammalian mucosa, was used as the standard and for stability testing. The biological activity of heparin was measured by the method of Jaques and Charles (1941), which utilizes the anticoagulant effect of heparin in vitro. Tubes containing serial dilutions of heparin were made up to $0.4 \mathrm{ml}$ with saline. To each tube was added $0.5 \mathrm{ml}$ of bovine plasma, followed by $0.1 \mathrm{ml}$ of a thrombin solution containing $1.75 \mathrm{U} / \mathrm{ml}$ in normal saline. The endpoint was judged as the minimum concentration of heparin which prevented clotting in an inverted tubeat $25^{\circ} \mathrm{C}$. 
The chemical stability of heparin was determined by metachromatic measurement of the light absorbance of a heparin/Azure-A complex. Two $\mathrm{ml}$ of $\mathrm{pH} 7.3$ phosphate buffer and $1 \mathrm{ml}$ of a solution containing $85 \mu \mathrm{g} / \mathrm{ml}$ Azure-A were added to tubes containing heparin in varying dilutions in normal saline. Readings were made using a no. 54 filter in a model 800-3 Klett colorimeter.

\section{HEPARIN STABILITY IN INTRAVENOUS} INFUSIONS

Heparin sodium was dissolved at a final concentration of $20 \mathrm{U} / \mathrm{ml}(10000 \mathrm{U} / 500 \mathrm{ml})$ in either sodium chloride $0.9 \%$ (pH 6.8), dextrose $5 \%(\mathrm{pH}$ 3.9 ), dextrose $4.3 \%$ with sodium chloride $0.18 \%$ (pH 3.9), compound sodium lactate injection (Hartmann's solution, Ringer-lactate solution, $\mathrm{pH}$ $6 \cdot 3$ ), or sodium lactate $1 / 6 \mathrm{M}(\mathrm{pH} 6 \cdot 3)$. Samples of the solutions were assayed for anticoagulant activity and chemical stability at one, four, eight, and 24 hours, during storage at room temperature (20$23^{\circ} \mathrm{C}$ ).

\section{HEPARIN STABILITY IN INTRAVENOUS} INFUSIONS CONTAINING ANTIBIOTICS Assays were repeated using the same concentrations of heparin sodium in solutions of sodium chloride $0.9 \%$ and dextrose $5 \%$ to which were added either sodium benzylpenicillin 1 mega unit $/ 500 \mathrm{ml}$, sodium ampicillin $5 \mathrm{~g} / 500 \mathrm{ml}$, or sodium methicillin $5 \mathrm{~g} / 500 \mathrm{ml}$. Control experiments showed that the penicillins did not interfere with the heparin assays.

The addition of erythromycin, cephaloridine, gentamicin, kanamycin, tetracycline, or oxytetracycline to solutions of heparin in sodium chloride $0.9 \%$ or dextrose $5 \%$ produced visible changes varying from cloudiness to heavy precipitation, and no further biological or chemical testing of these solutions was carried out.

\section{PENICILLIN ASSAYS}

Sodium benzylpenicillin (Purapen G, Beecham Research Laboratories) 10 mega units $/ 500 \mathrm{ml}$, sodium ampicillin (Penbritin, Beecham Research Laboratories) $5 \mathrm{~g} / 500 \mathrm{ml}$, or sodium methicillin (Celbenin, Beecham Research Laboratories) $5 \mathrm{~g} /$ $500 \mathrm{ml}$ was dissolved in either sodium chloride $0.9 \%(\mathrm{pH} 5 \cdot 2)$ or dextrose $5 \%$ (pH 4.0-4.2). Samples were then taken for initial measurements of pH and optical rotation and for iodometric assay of penicillin (British Pharmacopoeia, 1963). The assay method used involves a penicillin concentration of approximately $0.1 \% \mathrm{w} / \mathrm{v}$, and thus a 1 in 10 dilution of the sample was necessary. Solutions were stored at room temperature $\left(20-25^{\circ} \mathrm{C}\right)$ and sampling was repeated at six, 16, and 24 hours. One blank and two test estimations were made at each time interval. The mean initial assay value was taken to represent $100 \%$, and the six-, 16-, and 24-hour assay results could therefore be expressed as percentages of penicillin remaining. Iodine and thiosulphate reagents were freshly prepared daily

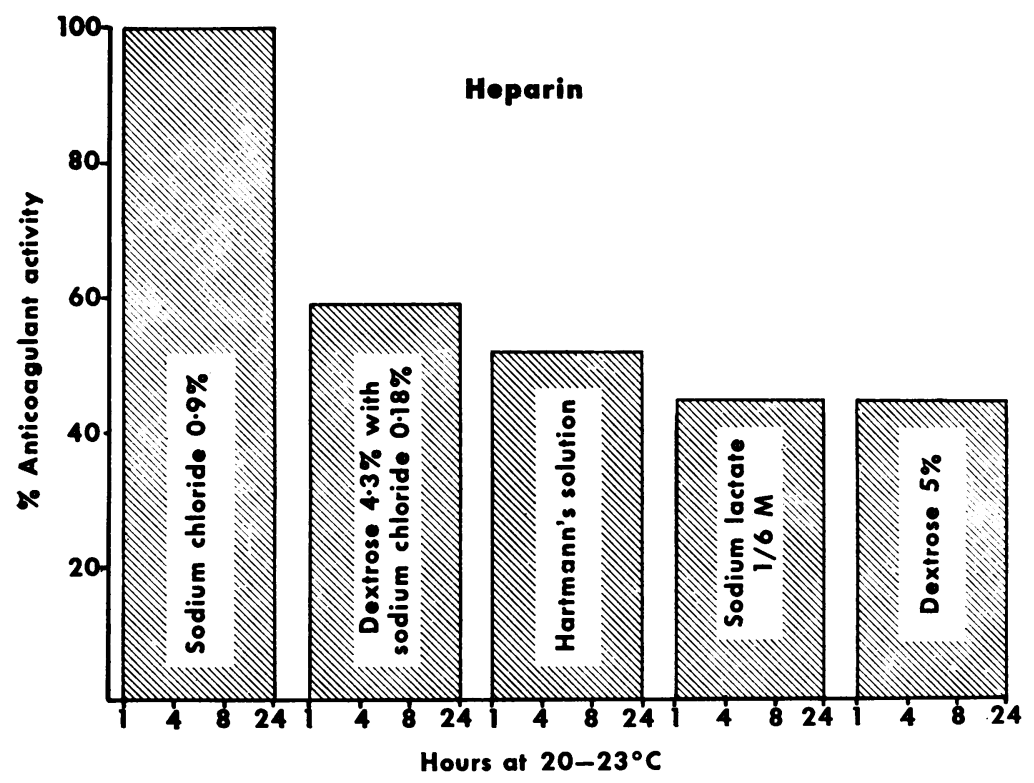

Fig 1 Anticoagulant activity of heparin (10000 U per 500 $\mathrm{ml}$ ) in five intravenous solutions over a 24-hour period. 
and standardized using the appropriate penicillin reference substance. The entire series of experiments was performed in duplicate.

The above procedure was repeated with the incorporation of $10000 \mathrm{U} / 500 \mathrm{ml}$ heparin sodium before the addition of the penicillin. Control determinations showed that heparin did not affect the iodometric assay of the penicillins.

\section{Results}

\section{HEPARIN STABILITIES}

Heparin remained stable and maintained full anticoagulant activity for 24 hours in normal saline at 20 to $23^{\circ} \mathrm{C}$. In comparison, a reduction of over $50 \%$ in anticoagulant effect was noted at initial assay in dextrose $5 \%$ and sodium lactate $1 / 6 \mathrm{M}$ (fig 1). Similarly, there was more than $40 \%$ reduction in anticoagulant activity at one hour in dextrose saline and Hartmann's solution (fig 1). Thereafter, the level of activity in each solution was constant for the remainder of the 24 hours. Results for chemical stability matched those for anticoagulant activity.

Assays of heparin in normal saline and dextrose $5 \%$ in the presence of benzylpenicillin, ampicillin, or methicillin gave values for stability and degree of activity similar to those obtained in the absence of these compounds. Heparin was therefore unaffected by the addition of the penicillins. In contrast, the other antibiotics tested all showed visible signs either of incompatibility or of limited stability in admixture with heparin. The results of these tests are summarised in the table.

PENICILLIN STABILITIES

Mean values for percentages of benzylpenicillin, ampicillin, and methicillin remaining at the various time intervals in normal saline and dextrose $5 \%$, both with and without the addition of heparin, are shown graphically in figures 2,3 , and 4 . It can be $\stackrel{\vec{\rho}}{\vec{g}}$

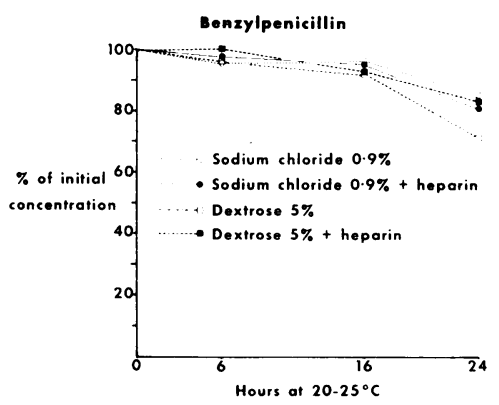

Fig 2 Stability of sodium benzylpenicillin (10 mega units per $500 \mathrm{ml}$ ) in sodium chloride $0.9 \%$ and dextrose $5 \%(a)$ without heparin and $(b)$ with heparin sodium $10000 \mathrm{U} / 500 \mathrm{ml}$.

seen that benzylpenicillin and ampicillin have good $\overrightarrow{0}$ stability in normal saline, and both antibiotigs maintain more than $90 \%$ of their activity for 106 hours at 20 to $25^{\circ} \mathrm{C}$. Heparin did not have a vegi marked effect. Ampicillin appeared to be slight more stable in saline in the presence of heparin (the differences were statistically significant at six $\frac{\mathscr{Q}}{\varnothing}$ and 16 hours), whereas decomposition of benzyl- $\varnothing$ penicillin was somewhat higher at 24 hours in the $\overrightarrow{\vec{O}}$ heparin-containing solution. Methicillin was stable 3 for six hours in normal saline whether or not heparin was present, with inactivation of less than $5 \%$ at this time. Thereafter, however, the solutions

\begin{tabular}{|c|c|c|}
\hline Antibiotic Added & Concentration & $\begin{array}{l}\text { Solution (Dextrose } 5 \%(D) \text { or Sodium Chloride } \\
0.9 \%(S) \text { Containing Heparin Sodium } 20 \mathrm{U} / \mathrm{ml} \text { ) }\end{array}$ \\
\hline $\begin{array}{l}\text { Erythromycin } \\
\text { lactobionate iv } \\
\text { (Erythrocin iv) }\end{array}$ & $\begin{array}{l}1.5 \mathrm{mg} / \mathrm{ml} \\
(300 \mathrm{mg} / 200 \mathrm{ml})\end{array}$ & $\begin{array}{l}\text { D Slight precipitate } \\
\text { S Precipitate }\end{array}$ \\
\hline $\begin{array}{l}\text { Cephaloridine } \\
\text { (Ceporan) }\end{array}$ & $\begin{array}{l}2 \mathrm{mg} / \mathrm{ml} \\
(1 \mathrm{~g} / 500 \mathrm{ml})\end{array}$ & $\begin{array}{l}\text { D Precipitate } \\
\text { S Precipitate }\end{array}$ \\
\hline $\begin{array}{l}\text { Gentamicin sulphate } \\
\text { (Garamycin) }\end{array}$ & $1 \mathrm{mg} / \mathrm{ml}$ & $\begin{array}{l}\text { D Opalescence } \\
\text { S Opalescence }\end{array}$ \\
\hline $\begin{array}{l}\text { Kanamycin sulphate } \\
\text { (Teva Labs) }\end{array}$ & $\begin{array}{l}2 \mathrm{mg} / \mathrm{ml} \\
(1 \mathrm{~g} / 500 \mathrm{ml})\end{array}$ & $\begin{array}{l}\text { D Precipitate } \\
\text { S Precipitate }\end{array}$ \\
\hline $\begin{array}{l}\text { Tetracycline iv } \\
\text { (Tevacycline iv) }\end{array}$ & $\begin{array}{l}1 \mathrm{mg} / \mathrm{ml} \\
(500 \mathrm{mg} / 500 \mathrm{ml})\end{array}$ & $\begin{array}{l}\text { D Heavy precipitate } \\
\text { S Clear for } 6 \text { hours only }\end{array}$ \\
\hline $\begin{array}{l}\text { Oxytetracycline iv } \\
\text { (Terramycin iv) }\end{array}$ & $\begin{array}{l}1 \mathrm{mg} / \mathrm{ml} \\
(500 \mathrm{mg} / 500 \mathrm{ml})\end{array}$ & $\begin{array}{l}\text { D Slight turbidity after } 4 \text { hours } \\
\text { S Slight turbidity after } 4 \text { hours }\end{array}$ \\
\hline
\end{tabular}

Table Effect of mixing heparin with various antibiotics in dextrose or normal saline 


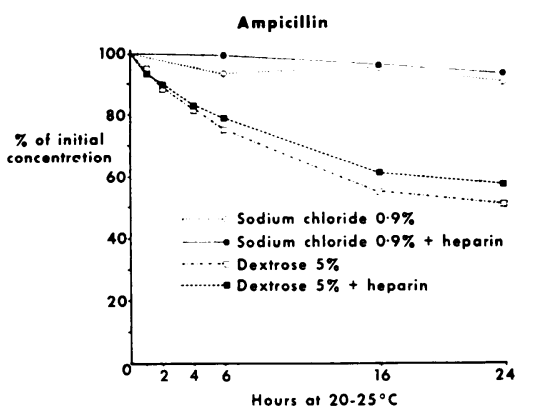

Fig 3 Stability of sodium ampicillin $(5 \mathrm{~g}$ per $500 \mathrm{ml}$ ) in sodium chloride $0.9 \%$ and dextrose $5 \%(a)$ without heparin and (b) with heparin sodium $10000 \mathrm{U} / 500 \mathrm{ml}$.

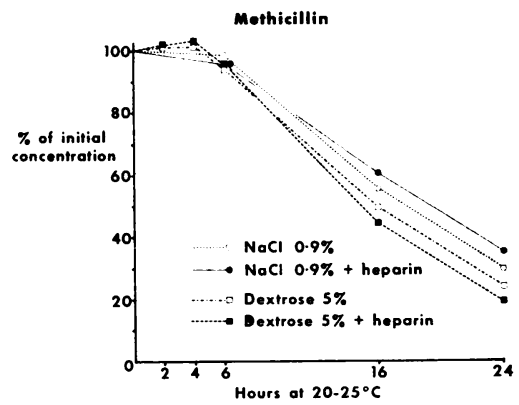

Fig 4 Stability of sodium methicillin $(5 \mathrm{~g}$ per $500 \mathrm{ml}$ ) in sodium chloride $0.9 \%$ and dextrose $5 \%(a)$ without heparin and (b) with heparin sodium $10000 \mathrm{U} / 500 \mathrm{ml}$.

became turbid, with 40 to $45 \%$ inactivation at 16 hours.

The most striking finding in the $5 \%$ dextrose solutions was the instability of ampicillin. Decomposition was at least $25 \%$ at six hours and approximately $45 \%$ at 16 hours, though the rate of decomposition then became slower. Heparin had a significant stabilizing effect on the antibiotic but the loss of potency was still unacceptable at six hours. Because of the marked degree of decomposition at six hours, it was decided to investigate the stability of ampicillin in 5\% dextrose before this time. These further studies showed that inactivation averaged about $5 \%$ at one hour, $12 \%$ at two hours, $19 \%$ at four hours, and $25 \%$ at six hours. Subsequent work using lower concentrations of ampicillin in $5 \%$ dextrose $(1$ or $2 \mathrm{~g} / 500 \mathrm{ml})$ has shown only marginally slower inactivation of the antibiotic (Lynn, 1973).

Benzylpenicillin retained more than $90 \%$ activity for 16 hours in $5 \%$ dextrose. Inactivation at 24 hours, however, was about $15 \%$ higher in dextrose than in normal saline. Heparin had a stabilizing effect on benzylpenicillin which was significant at six and 24 hours.

One of the three batches of methicillin tested in $5 \%$ dextrose solution showed an average decomposition of just over $10 \%$ at six hours, but the remaining two retained $95 \%$ or more of their activity at six hours. All three batches showed at least $95 \%$ activity at four hours, and infusions would certainly be satisfactory for this period. As in the saline solutions, precipitation took place between six and 16 hours (when the pH had fallen below about 4). Heparin did not have a significant effect on methicillin stability.

During analysis of the results, the significance of an effect was determined by the appropriate form of the $t$ test, at the $5 \%$ level.

\section{Discussion}

Conflicting statements on the stability of heparin in intravenous infusions appear in the literature. Pritchard (1964) noted that heparin solutions underwent rapid loss of potency when autoclaved at below $\mathrm{pH}$ 5, and suggested that the drug might lose activity at the relatively low $\mathrm{pH}$ of dextrose if mixed with this solution for any length of time. On the other hand, Parker (1969) reported that heparin was stable for 24 hours in $5 \%$ dextrose or normal saline. The choice of $5 \%$ dextrose as a vehicle for heparin administered by clockwork syringe pump (Handley, 1970) was criticized by O'Riordan and MacGowan (1970), who found heparin therapy very difficult to control when this solvent was used. The latter recommend the use of normal saline or Hartmann's solution. Stock and Warner (1971) found little or no loss of activity in 24 hours at room temperature when heparin was dissolved in $5 \%$ dextrose (pH 4.4). A lower limit of pH 3.5 is, however, allowed for dextrose injection BP.

In a recent report of a within-patient cross-over trial comparing dextrose $5 \%(\mathrm{pH} 3 \cdot 8-4 \cdot 5)$ and sorbitol $5 \%(\mathrm{pH} 6.2)$ as diluents for heparin, Chessells, Braithwaite, and Chamberlain (1972) found little variation in plasma herapin levels at three hours and 12 hours, although there was wider variation in the partial thromboplastin time with kaolin (PTTK) over this period.

In the tests in vitro reported here, there was more than a $50 \%$ fall in anticoagulant activity of heparin in $5 \%$ dextrose solution and about $40 \%$ reduction in activity in dextrose saline. Both intravenous solutions had an initial $\mathrm{pH}$ of 3.9 and the addition of heparin sodium raised this, on average, to just below $6 \cdot 0$. These losses of activity were noted at 
one hour and the levels of activity then remained constant throughout the rest of the 24-hour period of observation. This could account for the fact that the assays of Chessells et al (1972) failed to show any marked differences in plasma heparin level between three and 12 hours. Our results may also explain the clinical observations of O'Riordan and MacGowan (1970). Low pH of the vehicle is apparently not the only fact influencing the stability of heparin, however, since solutions containing lactate ions at $\mathrm{pH} 6.3$ were also found to lose about $50 \%$ activity. The present results show that heparin is most stable in normal saline of almost neutral $\mathrm{pH}$. The reason for the rapid initial decrease in heparin activity in intravenous fluids containing dextrose or lactate is unknown and should be the subject of further work.

According to the widely accepted criterion that intravenous infusion solutions containing an antibiotic should be used within a period which ensures that loss of activity does not exceed $10 \%$, this study has shown that normal saline infusions of benzylpenicillin and ampicillin are satisfactory for 16 hours and 24 hours, respectively, at room temperature. However, factors such as the serum concentration achieved, in relation to the site and nature of the infection and the sensitivity of the infecting organism, must also be taken into account in deciding upon the method, rate, and frequency of infusion (Lynn, 1971). Methicillin is less stable in normal saline, and in view of the results of this study and earlier work (Lynn, 1970), it should be infused within six hours.

It is clear that the stability of ampicillin in dextrose and other carbohydrate solutions is very limited (Lynn, 1970, 1971). Decomposition was even more rapid than had been indicated by previous work using microbiological assay techniques (Lynn, 1970; Jacobs, Nathan, Superstine, and Sacks, 1970) but the present results agree with other recently published findings (Hiranaka, Frazier, and Gallelli, 1972). Ampicillin is an amino acid with marked buffering properties, and solutions of the sodium salt are alkaline. It was noted that addition of $1-5 \mathrm{~g}$ sodium ampicillin to $500 \mathrm{ml}$ dextrose $5 \%$ raised the $\mathrm{pH}$ from $4 \cdot 1 / 4 \cdot 3$ to $8 \cdot 5 / 8 \cdot 9$ : at 24 hours the $\mathrm{pH}$ was still in the region of 8.0 . In this $\mathrm{pH}$ range, decomposition of penicillins in carbohydrate solutions is accelerated (Simberkoff, Thomas, McGregor, Shenkein, and Levine, 1970). The results of this study indicate that solutions of sodium ampicillin in 5\% dextrose should be infused within one to two hours (preferably within one hour) of preparation. Since this period would tend to be exceeded in practice, it would seem preferable for the antibiotic to be given by bolus injection into the infusion tubing, and not to be added to the fluid in the bottle. Benzylpenicillin and methicill 'n should be infused within 16 hours and four hours, respectively, when dissolved in dextrose fluids.

Apart from the three penicillins, all of the antibiotics tested were unsuitable for simultaneous administration with heparin in dextrose or saline infusions. In contrast, no important interactions took place between heparin and benzylpenicillin, ampicillin, or methicillin. In heparin/benzylpenicillin mixtures in normal saline both drugs were stable at room temperature for 16 hours, while in heparin/ ampicillin mixtures both agents were stable for 24 hours. The limiting factor with mixtures of heparin and methicillin in normal saline is the instability of the antibiotic, and solutions should be infused within six hours.

Thanks are due to Professor G. Izak, Director of Hematological Services, Rothschild Hadassah University Hospital, Jerusalem, for help and advice during the preparation of this work. We are also grateful to Miss J. Ashwin, Beecham Research Laboratories, Worthing, Sussex, for cooperation in arranging this study, and to Mrs A. Cotterell and $\mathrm{Mr} \mathrm{S}$. Paterson for technical assistance. W8 are indebted to Mr S. J. Lomax for drawing the figures and to Mrs W. M. Atkins and Miss E. A Thom for statistical analysis.

\section{References}

British Pharmacopoeia (1963). Benzylpenicillin, pp. 94-97. Pharmaceutical Press, London.

Chessells, J. M., Braithwaite, T. A., and Chamberlain, D. A. (1972). Dextrose and sorbitol as diluents for continuous intravenous heparin infusion. Brit. med. J., 2, 81-82.

Handley, A. J. (1970). Portable heparin injector. Lancet, 2, 313-314.

Hiranaka, P. K., Frazier, A. G., and Gallelli, J. F. (1972). Stability of sodium ampicillin in aqueous solutions. Amer. J. Hosp. Pharm., 29, 321-322.

Jacobs, J. (1972). Unpublished survey.

Jacobs, J., Nathan, I., Superstine, E., and Sacks, T. (1970). Ampicillin and carbenicillin stability in commonly used infusion solutions Drug Intell. clin. Pharm., 4, 204-208.

Jaques, L. B., and Charles, A. F. (1941). The assay of heparin. Quart. J. Pharm. Pharmacol., 14, 1-15

Lynn, B. (1970). Pharmaceutical aspects of semi-synthetic penicillins. J. hosp. Pharm., 28, 71-86.

Lynn, B. (1971). Recent work on parenteral penicillins. J. hosp. Pharm. 29, 183-194.

Lynn, B. (1973). Inactivation of ampicillin in dextrose solutions. (To be published).

O'Riordan, J., and MacGowan, W. (1970). Portable heparin injector. Lancet, 2, 521.

Parker, E. A. (1969). Panheprin injection. Amer. J. Hosp. Pharm. 26,655 .

Preston, F. E., Malia, R. G., Sworn, M. J., and Blackburn, E. K. (1973). Intravascular coagulation and $E$. coli septicaemia. J. clin. Path., 26, 120-125.

Pritchard, J. (1964). Stability of heparin solutions. J. Pharm. Pharmacol., 16, 487-489.

Simberkoff, M. S., Thomas, L., McGregor, D., Shenkein, I., and Levine, B. B. (1970). Inactivation of penicillins by carbohydrate solutions at alkaline pH. New Engl. J. Med., 283, 116-119.

Stock, S. L., and Warner, N. (1971). Heparin in acid solutions. Brit. med. J., 3, 307. 